\title{
Incidence of Post-Ureteric Reimplantation Urinary Tract Infection in Primary Vesicoureteral Reflux
}

\author{
Bhanu Mariyappa ${ }^{\mathrm{a}, \mathrm{c}}$, Shobana Maruthayanar ${ }^{\mathrm{b}}$, Naeem Samnakay ${ }^{\mathrm{b}}$, Andrew Barker ${ }^{\mathrm{b}}$, \\ Japinder Khosa ${ }^{\mathrm{b}}$
}

\begin{abstract}
Background: The goal of treatment in vesicoureteral reflux (VUR) is to reduce the risk of reflux-associated pyelonephritis. Medical versus surgical treatment for VUR is still controversial, with surgery successful in majority of cases. There are not enough data available in literature on long-term incidence of urinary tract infection (UTI) after reimplantation. The aim of the study was to determine the long-term outcome after reimplantation with respect to UTI, renal scarring and potential risk factors for post-reimplant UTI.
\end{abstract}

Methods: It is a retrospective review of 106 consecutive cases who underwent reimplantation for primary VUR.

Results: Incidence of post-reimplant UTI is $12.8 \%$. Majority of our patients were females and showed high grade reflux. Median age at surgery was 32 months. Thirteen patients had post-reimplant UTI. Of this, $12 / 13$ were females, $12 / 13$ had pre-reimplant febrile UTI, 10/13 had high grade VUR, 7/13 had urge incontinence and dysfunctional voiding, and 3/13 had constipation. Only two patients showed new scarring/worsening scarring.

Conclusions: It is an established fact that ureteric reimplantation is effective in preventing UTI. Some continue to develop UTI even after successful correction of VUR and it is unclear as to why it happens. Various rates of post-reimplant UTI have been quoted in literature with non-febrile UTI of $40 \%$ and febrile UTI of $14 \%$. In our study, febrile UTI rate was $4.9 \%$ and non-febrile UTI rate was $7.9 \%$. Postreimplant UTI resulting in new renal scars is rare. There are some possible risk factors for recurrent UTI after reimplantation, but unfortunately only few of them are reversible (bowel bladder dysfunction). Reimplantation for VUR is a very effective treatment. Incidence of post-reimplant UTI is $12.8 \%$ with development of new scars after such UTI is rare. Several risk factors contribute to such UTI.

Manuscript accepted for publication October 09, 2015

${ }^{a}$ Townsville Hospital, 100, Angus Smith Drive, Douglas, QLD 4814, Australia bPrincess Margaret Hospital for Children, Roberts Road, Subiaco, Perth 6008 , Western Australia, Australia

${ }^{\mathrm{c}}$ Corresponding Author: Bhanu Mariyappa, Townsville Hospital, 100, Angus Smith Drive, Douglas, QLD 4814, Australia. Email: tvkbhanu@yahoo.com

doi: http://dx.doi.org/10.14740/wjnu237w
Keywords: Vesicoureteral reflux; Ureteric reimplantation; Urinary tract infection; Renal scarring

\section{Introduction}

Vesicoureteral reflux (VUR) is the most common urological anomaly in children, affecting about $1 \%$ general population [1]. Primary VUR is seen in $20 \%$ of neonates investigated for prenatal hydronephrosis [2]. VUR is a risk factor for recurrent urinary tract infection (UTI), pyelonephritis, renal scarring, hypertension and progressive renal failure.

Approximately $20 \%$ of affected children show changes on initial DMSA scan [3]. The goal of treatment in VUR is to reduce the risk of reflux-associated pyelonephritis and renal scarring. Medical versus surgical treatment for VUR is still a very controversial topic. Generally accepted indications for surgery are persisting high grade reflux, breakthrough infections, appearance of new scar, non-compliance with antibiotic prophylaxis and parental wishes. Ureteric reimplantation affords a success rate of $95-98 \%$ with low complication rate [4, 5]. There are limited data in the literature on the long-term incidence of UTI after reimplantation. The purpose of this study was to perform a retrospective review of long-term outcome after ureteric reimplantation with respect to incidence of febrile and non-febrile UTI, and new renal scarring and to identify potential risk factors for post-reimplant UTI.

\section{Materials and Methods}

A retrospective review of 106 consecutive patients who underwent ureteric reimplantation for primary VUR in the last 10 years was performed. Cases of VUR secondary to bladder outlet obstruction, neuropathic bladder, reflux in duplex system, reflux in a solitary kidney and those who were treated endoscopically with deflux were excluded from the study. Five cases who were lost to follow-up or moved interstate were also excluded from the study. VUR was diagnosed in all cases by micturating cystourethrogram (MCU) after a documented UTI or while evaluating antenatally detected hydroureteronephrosis. VUR was graded as per International Reflux Study Committee (IRSC) [6]. All cases had DMSA scan pre-operatively 
to document dysplasia or scarring and split renal function. The indication for surgery was noted in each case. All cases underwent cross-trigonal Cohen's ureteric reimplantation. Postoperatively cases were followed up with renal USS for renal growth and hydronephrosis. Repeat MCU and DMSA scans were done only in cases who continued to have febrile UTI. All cases with post-reimplant UTI underwent evaluation for bladder and bowel dysfunction with bladder and bowel diaries and uroflowmetry.

\section{Results}

Of 101 cases, there were 37 boys and 64 girls. In 84 cases, VUR was detected after an episode of UTI (68 febrile and 16 non-febrile) and in 17 cases, it was detected while investigating for antenatal hydroureteronephrosis. VUR was unilateral in 36 cases and bilateral in 65 cases. The refluxing units were grade 1 in nine, grade 2 in 23, grade 3 in 49, grade 4 in 59 and grade 5 in 26. DMSA scan showed changes in 36 cases at presentation, of which 32 presented with UTI and all of them had grade 3 reflux and above.

All patients had Cohen's reimplantation. Age at surgery ranged from 4 months to 15 years with a median age of 32 months at surgery. The follow-up period ranged from 26 to 120 months with a mean follow-up period of 42 months.

Thirteen patients had post-operative UTI, of which 12 were females. Five out of 13 patients had febrile UTI and 8/13 had non-febrile UTI.

Seven out of 13 patients had symptoms of urge incontinence or dysfunctional voiding diagnosed with bladder diary and uroflowmetry. Three had constipation based on clinical history, abdominal X-ray and bowel diary.

All five patients with post-reimplant febrile UTI had MCU, demonstrating recurrent VUR in only 2/5 cases. Three out of five cases with three or more episodes of non-febrile UTI also had MCU based on surgeon's preference but none of them showed recurrent VUR.

DMSA scan was done in all five post-reimplant febrile UTI cases, showing new scarring in $2 / 5$ cases. In the other eight cases of non-febrile UTI, renal growth/damage was assessed by USS showing appropriate renal growth for age without new scars.

\section{Discussion}

The goal of surgical correction in VUR is to prevent pyelonephritis and new renal scarring. Shimada et al [7] have shown that affected kidneys could not catch up with normal kidneys after successful reimplant, but they can grow at a rate parallel to the expected growth curve. Hence, it is important to reimplant to prevent kidney damage or further damage.

It is a well-established fact that ureteric reimplantation is very effective in preventing UTI. In a study by Matsumoto et al [8], frequency of febrile UTI dramatically dropped from 0.23538 pre-operatively to 0.00894 and 0.00081 per patient per month at 6 and 12 months after surgery, respectively. However, some children continue to develop UTI even after successful correction of VUR and it is unclear as to why it happens.

The incidence of UTI after reimplant is significantly lower compared to medically treated group. In the final report of the International Reflux Study, 32/127 medically treated children compared to $17 / 125$ surgically treated children developed UTI $(\mathrm{P}<0.03)$ [9].

The European arm of IRSC study showed, at the end of 10-year follow-up, non-febrile UTI rate of $40 \%$ and febrile UTI of $14 \%$ after reimplantation surgery [9]. Whittam et al [10] in their large series showed UTI rate of $31 \%$ and febrile UTI rate of $4.6 \%$ after an average follow-up of 15 months and a significant number of these cases had dysfunctional elimination syndrome. In two recently published articles, non-febrile UTI was $15 \%$ and $15.6 \%$ whereas febrile UTI was $0.6 \%$ and $4.1 \%[11,12]$. In our study, the incidence was $7.9 \%$ of nonfebrile UTI and $4.9 \%$ of febrile UTI.

It is also important to note that the risk of post-reimplant UTI continues into adult life. Beetz et al [3] reported a rate of febrile UTI of $16 \%$ and non-febrile UTI of 38\% after a followup of 20 years.

In previous studies, about $20-39 \%$ children diagnosed with VUR showed renal changes on initial DMSA scan $[3,11]$. It was comparable to our study at $31.3 \%$. With regard to postreimplant renal scarring, the reported scarring rate is highly variable. In Birmingham study, the incidence of post-reimplant scarring was reported at 5.2\% [13], whereas in European arm of International Reflux Study, it was 17.2\% [14]. In both these studies scarring was detected by IVP studies. DMSA scan is the most sensitive tool for detecting renal scars $[15,16]$. Renal deterioration on DMSA scan is defined as a decrease in differential function of greater than $3 \%$ in a renal unit [17]. The incidence of new renal scars after ureteric reimplantation when assessed with DMSA scan is only about $2 \%$ [18]. In our study, we did not do DMSA scan routinely to prevent trauma and radiation exposure from nuclear imaging. Out of 13 cases with post-reimplant UTI, all five with febrile UTI had DMSA scan, of which new scarring was seen only in two, similar to observation made by Webster et al [18]. These are the only two cases which showed recurrent reflux on MCU. In the remaining eight cases, assessment of kidney damage was by renal USS and all eight cases showed good renal growth without any scarring.

Possible risk factors for post-reimplant UTI are female sex, previous breakthrough infection, high grade reflux and pre-operative renal scarring [12]. Recently published Swedish reflux study found that girls with high grade VUR had significantly higher rate of recurrent febrile UTI than boys [19]. Our study concurs with some of the observations made by Nelson and Brandstromp.

The risk factors for post-reimplant UTI identified in our study were female sex in 12/13 cases, pre-reimplant febrile UTI in 12/13 cases, high grade VUR in 10/13 cases and bowel bladder dysfunction in 10/13 cases.

\section{Conclusions}

Incidence of post-reimplantation UTI $(12.8 \%)$ is low and that of febrile UTI $(4.95 \%)$ is even lower. Female sex, pre-reimplant 
febrile UTI, high grade reflux and presence of bladder bowel dysfunction are risk factors for post-reimplant UTI. Development of new renal scar after post-reimplant UTI is very rare.

\section{Conflict of Interest}

None.

\section{Funding}

None.

\section{References}

1. Jacobson SH, Hansson S, Jakobsson B. Vesico-ureteric reflux: occurrence and long-term risks. Acta Paediatr Suppl. 1999;88(431):22-30.

2. Yeung CK, Godley ML, Dhillon HK, Gordon I, Duffy PG, Ransley PG. The characteristics of primary vesicoureteric reflux in male and female infants with pre-natal hydronephrosis. Br J Urol. 1997;80(2):319-327.

3. Beetz R, Mannhardt W, Fisch M, Stein R, Thuroff JW. Long-term followup of 158 young adults surgically treated for vesicoureteral reflux in childhood: the ongoing risk of urinary tract infections. J Urol. 2002;168(2):704-707; discussion 707.

4. Elder JS, Peters CA, Arant BS, Jr., Ewalt DH, Hawtrey CE, Hurwitz RS, Parrott TS, et al. Pediatric Vesicoureteral Reflux Guidelines Panel summary report on the management of primary vesicoureteral reflux in children. J Urol. 1997;157(5):1846-1851.

5. Skoog SJ, Peters CA, Arant BS, Jr., Copp HL, Elder JS, Hudson RG, Khoury AE, et al. Pediatric Vesicoureteral Reflux Guidelines Panel Summary Report: Clinical Practice Guidelines for Screening Siblings of Children With Vesicoureteral Reflux and Neonates/Infants With Prenatal Hydronephrosis. J Urol. 2010;184(3):1145-1151.

6. Medical versus surgical treatment of primary vesicoureteral reflux: report of the International Reflux Study Committee. Pediatrics. 1981;67(3):392-400.

7. Shimada K, Matsui T, Ogino T, Arima M, Mori Y, Ikoma F. Renal growth and progression of reflux nephropathy in children with vesicoureteral reflux. J Urol. 1988;140(5 Pt 2):1097-1100.

8. Matsumoto F, Tohda A, Shimada K. Effect of ureteral reimplantation on prevention of urinary tract infection and renal growth in infants with primary vesicoureteral reflux. Int J Urol. 2004;11(12):1065-1069.

9. Jodal U, Smellie JM, Lax H, Hoyer PF. Ten-year results of randomized treatment of children with severe vesicoureteral reflux. Final report of the International Reflux Study in Children. Pediatr Nephrol. 2006;21(6):785-792.

10. Whittam BM, Thomasch JR, Makari JH, Tanaka ST, Thomas JC, Pope JCt, Adams MC, et al. Febrile urinary tract infection after ureteroneocystostomy: a contemporary assessment at a single institution. J Urol. 2010;183(2):688-692.

11. Yeoh JS, Greenfield SP, Adal AY, Williot P. The incidence of urinary tract infection after open anti-reflux surgery for primary vesicoureteral reflux: early and long-term follow up. J Pediatr Urol. 2013;9(4):503-508.

12. Nelson CP, Hubert KC, Kokorowski PJ, Huang L, Prasad MM, Rosoklija I, Retik AB. Long-term incidence of urinary tract infection after ureteral reimplantation for primary vesicoureteral reflux. J Pediatr Urol. 2013;9(1):9298.

13. Prospective trial of operative versus non-operative treatment of severe vesicoureteric reflux in children: five years' observation. Birmingham Reflux Study Group. Br Med J (Clin Res Ed). 1987;295(6592):237-241.

14. Smellie JM, Tamminen-Mobius T, Olbing H, Claesson I, Wikstad I, Jodal U, Seppanen U. Five-year study of medical or surgical treatment in children with severe reflux: radiological renal findings. The International Reflux Study in Children. Pediatr Nephrol. 1992;6(3):223-230.

15. Goldraich NP, Ramos OL, Goldraich IH. Urography versus DMSA scan in children with vesicoureteric reflux. Pediatr Nephrol. 1989;3(1):1-5.

16. Farnsworth RH, Rossleigh MA, Leighton DM, Bass SJ, Rosenberg AR. The detection of reflux nephropathy in infants by 99 mtechnetium dimercaptosuccinic acid studies. J Urol. 1991;145(3):542-546.

17. Piepsz A, Tamminen-Mobius T, Reiners C, Heikkila J, Kivisaari A, Nilsson NJ, Sixt R, et al. Five-year study of medical or surgical treatment in children with severe vesico-ureteral reflux dimercaptosuccinic acid findings. International Reflux Study Group in Europe. Eur J Pediatr. 1998;157(9):753-758.

18. Webster RI, Smith G, Farnsworth RH, Rossleigh MA, Rosenberg AR, Kainer G. Low incidence of new renal scars after ureteral reimplantation for vesicoureteral reflux in children: a prospective study. J Urol. 2000;163(6):19151918.

19. Brandstrom P, Esbjorner E, Herthelius M, Swerkersson S, Jodal U, Hansson S. The Swedish reflux trial in children: III. Urinary tract infection pattern. J Urol. 2010;184(1):286-291. 